PREPARED FOR THE U.S. DEPARTMENT OF ENERGY, UNDER CONTRACT DE-AC02-76CH03073

PPPL-3704

PPPL-3704

UC-70

Core Fueling and Edge Particle Flux Analysis in Ohmically and Auxiliary Heated NSTX Plasmas

by

V.A. Soukhanovskii, R. Maingi, R. Raman, H.W. Kugel, B.P. LeBlanc, L. Roquemore, C.H. Skinner, and NSTX Research Team

June 2002

NM|

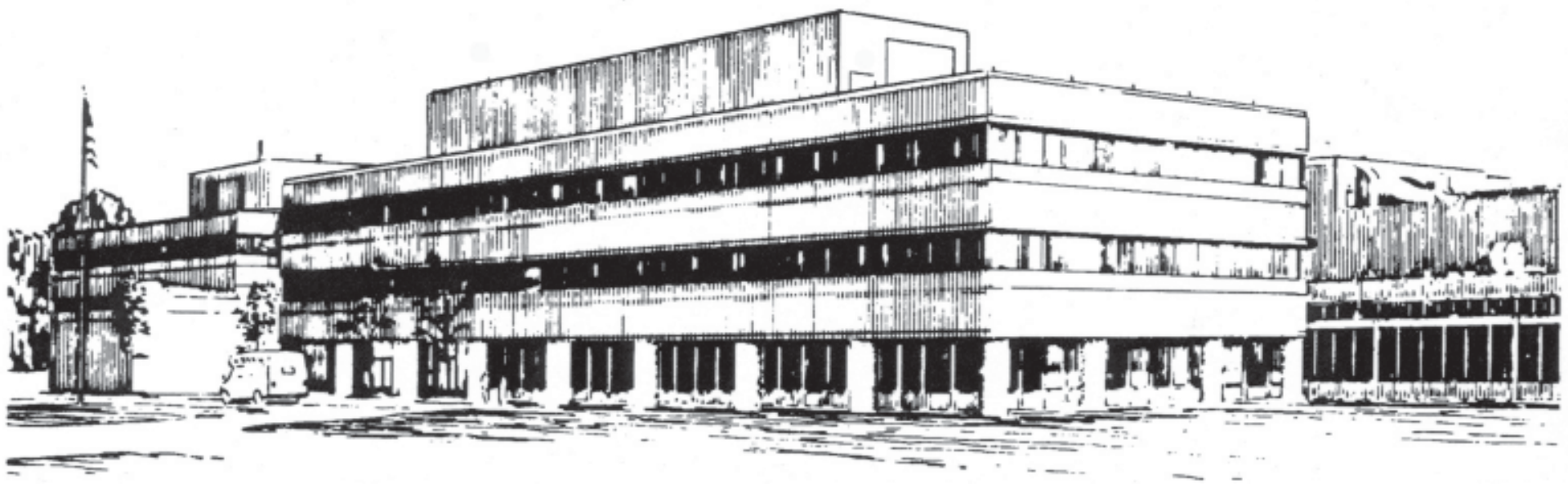

PRINCETON PLASMA PHYSICS LABORATORY PRINCETON UNIVERSITY, PRINCETON, NEW JERSEY 


\section{PPPL Reports Disclaimer}

This report was prepared as an account of work sponsored by an agency of the United States Government. Neither the United States Government nor any agency thereof, nor any of their employees, makes any warranty, express or implied, or assumes any legal liability or responsibility for the accuracy, completeness, or usefulness of any information, apparatus, product, or process disclosed, or represents that its use would not infringe privately owned rights. Reference herein to any specific commercial product, process, or service by trade name, trademark, manufacturer, or otherwise, does not necessarily constitute or imply its endorsement, recommendation, or favoring by the United States Government or any agency thereof. The views and opinions of authors expressed herein do not necessarily state or reflect those of the United States Government or any agency thereof.

\section{Availability}

This report is posted on the U.S. Department of Energy's Princeton Plasma Physics Laboratory Publications and Reports web site in Fiscal Year 2002. The home page for PPPL Reports and Publications is: http://www.pppl.gov/pub_report/

DOE and DOE Contractors can obtain copies of this report from:

U.S. Department of Energy

Office of Scientific and Technical Information

DOE Technical Information Services (DTIS)

P.O. Box 62

Oak Ridge, TN 37831

Telephone: (865) 576-8401

Fax: (865) 576-5728

Email: reports@adonis.osti.gov

This report is available to the general public from:

National Technical Information Service

U.S. Department of Commerce

5285 Port Royal Road

Springfield, VA 22161

Telephone: 1-800-553-6847 or

(703) 605-6000

Fax: (703) 321-8547

Internet: http://www.ntis.gov/ordering.htm 


\author{
V. A. Soukhanovskii ${ }^{\mathrm{a}, 1}$, R. Maingi ${ }^{\mathrm{b}}, \mathrm{R} \cdot \operatorname{Raman}^{\mathrm{c}}$, \\ H. W. Kugel ${ }^{\text {a }}$, B. P. LeBlanc ${ }^{\text {a }}$, L. Roquemore ${ }^{\text {a }}$, \\ C. H. Skinner ${ }^{\text {a }}$, and NSTX Research Team \\ a Princeton Plasma Physics Laboratory, Princeton, NJ 08543, USA \\ ${ }^{\mathrm{b}}$ Oak Ridge National Laboratory, Oak Ridge, TN 37831, USA \\ ${ }^{c}$ University of Washington, Seattle, WA 98195, USA
}

\title{
Core fueling and edge particle flux analysis in ohmically and auxiliary heated NSTX plasmas.
}

\begin{abstract}
The Boundary Physics program of the National Spherical Tor us Experiment (NSTX) is focusing on optimization of the edge power and particle flows in $\beta \geq 25 \% \mathrm{~L}$ - and $\mathrm{H}$-mode plasmas of $t \leq 0.8 \mathrm{~s}$ duration heated by up to $6 \mathrm{MW}$ of high harmonic fast wave and up to $5 \mathrm{MW}$ of neutral beam injection. Particle balance and core fueling efficiencies of low and high field side gas fueling of L-mode ohmic and NBI heated plasmas have been compared using an analytical zero dimensional particle balance model and measured ion and neutral fluxes. Gas fueling efficiencies are in the range of $0.05-0.20$ and do not depend on discharge magnetic configuration, density or poloidal location of the injector. The particle balance modeling indicates that the addition of HFS fueling results in a reversal of the wall loading rate and higher wall inventories. Initial particle source estimates obtained from neutral pressure and spectroscopic measurements indicate that ion flux into the divertor greatly exceeds midplane ion flux from the main plasma, suggesting that the scrape-off cross-field transport plays a minor role in diverted plasmas. Present analysis provides the basis for detailed fluid modeling of core and edge particle flows and particle confinement properties of NSTX plasmas. This research was supported by the U.S. Department of Energy under contracts No. DE-AC02-76CH03073, DE-AC05-00OR22725, and W-7405-ENG-36.
\end{abstract}

Key words: spherical torus, fueling, particle balance PACS:

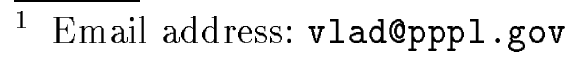

Preprint submitted to Elsevier Preprint

26 May 2002 


\section{Introduction}

The focus of the National Spherical Torus Experiment (NSTX) Boundary Physics program is the optimization of the edge power and particle flows in $\beta \geq 25 \%$ long pulse L- and H-mode plasmas heated by up to $6 \mathrm{MW}$ of high harmonic fast wave (HHFW) power and up to $5 \mathrm{MW}$ of neutral beam injection (NBI). It has been initially thought that conventional tokamak power and particle handling techniques would be challenged by the spherical tori (ST) features, such as the compactness of the divertor and the scrape-off layer (SOL) width, resulting from the short connection length and high mirror ratio. NSTX has successfully achieved NBI heated and HHFW heated H-mode plasmas of several $\tau_{E}$ duration and stored energy up to $E \leq 200 \mathrm{~kJ}$ and plasmas with $\beta_{t} \leq 30 \%$ thus demonstrating that the conventional techniques are adequate for $t \leq 0.8 \mathrm{~s}$ duration high performing ST target plasma. The purpose of this paper is to provide an initial analysis of global particle balance in NSTX and an assessment of the efficiency of the core fueling and divertor performance. This global approach helps identify the pathways for further detailed analysis of particle confinement, core density limiting mechanisms, and scrape-off layer transport, involving multi-fluid numerical modeling of edge plasmas [1].

\section{Experiment and diagnostics}

External fueling of NSTX plasmas is achieved by neutral gas injectors and neutral beam injectors. Top and midplane fast piezoelectric valves are referred to as the low field side (LFS) injectors. The valves provide a well-controlled continuous gas flow at a rate $\Gamma_{\text {gas }} \leq 170$ torr $\cdot 1 / \mathrm{s}$ per injector. The high field side (HFS) gas injector was recently installed on NSTX following successful MAST demonstration of improved $\mathrm{H}$-mode access with inner wall gas fueling. The gas injector provides a pseudo-constant flow at a rate $\Gamma_{g a s} \leq 50$ torr.1 / s. Three $E \leq 90 \mathrm{keV}$ deuterium beams injected co-directionally with plasma current at three radii of $r_{1}=48.7, r_{2}=59.2, r_{3}=64.9 \mathrm{~cm}$ yield the fueling rate of $\Gamma_{N B I} \simeq 1.3$ torr.l / s per $1 \mathrm{MW}$ of $\mathrm{NBI}$ power.

Quantitative particle balance analysis utilizes the measurements of several diagnostics. These are fast neutral pressure gauges, including two calibrated ionization gauges in the midplane, and two Penning gauges in upper and lower divertors. Plasma profiles are measured by a tangential multi-point Thomson scattering (MPTS) system. Various spectroscopic diagnostics include optically filtered detectors of impurity, visible bremsstrahlung, and the deuterium Balmer line emissions, and visible and VUV spectrometers. Especially useful for neutral recycling measurements are the photometrically and spatially calibrated 2048-pixel optically filtered CCD arrays, viewing the lower divertor 
neutralizer plates and the center stack tiles.

A database of about 70 inner wall limited (IWL), lower single null (LSN) and double null (DN) diverted discharges has been used in the present analysis. The discharges included $0.8-1.0 \mathrm{MA}$ ohmically and NBI heated fiducial L-mode deuterium plasmas, and the L-mode ohmic discharges obtained in a density scan experiment. Fueling efficiencies have been determined in the current ramp-up and flat-top phases of the discharge since many plasmas after $t \leq 0.25 \mathrm{~s}$ experience MHD modes or reconnection events (RE's) altering plasma parameters.

\section{Particle balance and fueling efficiency}

A global particle balance equation (PBE) (for example, [2]) is applied to each discharge to analyze core plasma contribution of various particle sources and sinks:

$$
\frac{d N_{i}}{d t}=\Gamma_{g a s}+\Gamma_{N B I}+\Gamma_{N B I-\text { cold }}-\Gamma_{N B I-c r y o}-\Gamma_{w a l l}-\Gamma_{\text {pump }}-\frac{d N_{n}}{d t}(1)
$$

The change in total deuteron inventory $d N_{i} / d t$ is derived from the measured $Z_{e f f}$ and the volume-averaged density $N_{e} \simeq \bar{n}_{e} V_{p} . \Gamma_{g a s}$ is the total gas injector rate. $\Gamma_{N B I}$ is the NBI fueling rate, $\Gamma_{N B I-\text { cold }} \simeq 0.25 \times \Gamma_{N B I}$ is the NBI line neutral gas fueling rate, and $\Gamma_{N B I-c r y o}$ is the NBI line cryopump rate. Inclusion of the latter term is important: noticeable effect on plasma performance is observed when the NBI duct is open to NSTX vacuum vessel. It is estimated from the cryopump pumping speed of $5 \times 10^{4} \mathrm{~L} / \mathrm{s}$ and neutral pressure measurements. The last two terms in PBE are the neutral gas build-up rate $d N_{n} / d t$ and the turbomolecular pump rate $\Gamma_{\text {pump }}$. The wall loading rate $\Gamma_{\text {wall }}$ is derived from the balance equation. Integrating the equation yields the cumulative particle inventories. Fueling efficiency is defined as $\eta=N_{p} / N_{\text {ext }}$, where $N_{p}$ is the total number of particles enclosed by the last closed flux surface (LCFS), and $N_{e x t}$ is the total number of particles introduced externally into the vacuum vessel. Fueling efficiency $\eta$ characterizes individual source contribution to the global particle inventory, as thermal and fast particle transport and confinement properties are different. Instantaneous fueling efficiency may be defined as $\eta_{\tau}=\left(d N_{i} / d t\right) \Gamma_{g a s}^{-1}$. It is determined by the transitory particle balance and is usually lower than $\eta$. Shown in Figure 1 are the PBE results for a LFS (top injector) fueled DN discharge with the following parameters: $I_{p}=1 \mathrm{MA} P_{N B I}=1.6 \mathrm{MW}$, line average density $\bar{n}_{e} \simeq 2.55 \times 10^{13} \mathrm{~cm}^{-3}$. The wall loading rate is positive through the gas pulse duration indicating strong pumping by the walls. After the gas is shut-off, the balance is dominated by the $d N_{i} / d t$ term, which slowly falls to $10-20$ torr $\cdot 1 / \mathrm{s}$, but still being 
larger than the total NBI fueling rate of $\Gamma_{N B I}+\Gamma_{N B I-\text { cold }} \leq 2$ torr $\cdot 1 / \mathrm{s}$. The wall loading rate becomes negative indicating that the wall starts degassing. This behavior is characteristic for most L-mode discharges fueled in the initial phase of the discharge from the LFS injectors. Improved plasma control and a higher central plasma density limit due to fueling have been achieved with LFS+HFS fueling. More importantly, the introduction of LFS+HFS fueling allowed for greater reproduceability and control of the $\mathrm{L}-\mathrm{H}$ transition and edge localized modes in the H-mode plasmas. Shown in Figure 2 are the PBE quantities derived for an otherwise similar discharge $\left(I_{p}=1 \mathrm{MA}, P_{N B I}=1.6\right.$ MW, line average density $\bar{n}_{e} \simeq 3.60 \times 10^{13} \mathrm{~cm}^{-3}$ ) with additional fueling from HFS injector. The HFS injection starts at $t=-0.26 \mathrm{~s}$ and produces a fueling rate burst at $0.09 \mathrm{~s}$ when the gas pulse reaches the plasma. Thereafter, a pseudo-constant rate of about 20 torr.1/s is maintained from HFS injector through a discharge. This rate is sufficient to change the particle balance so that $\Gamma_{\text {wall }}$ becomes positive, indicating that the wall is pumping. The physical interpretation of this result demonstrates the usefulness and limitations of the modeling with a one reservoir PBE. Recycling of neutrals from the wall is independent or weakly dependent on external fueling, thus "pumping" or "degassing" are interpreted as a net balance of all time-dependent source and sink rates of the particles confined with a finite time $\tau$. More sophisticated multi-reservoir equations include the effects of particle residence time in the SOL, divertor, or the wall surface [1]. For the present fueling analysis, however, the model adequately describes the relative importance of particle sources and sinks in NSTX. In most L-mode discharges fueled with $\Gamma_{\text {gas }} \leq 170$ torr $1 / \mathrm{s}$ and attained $\bar{n}_{e} \leq 5.5 \times 10^{13} \mathrm{~cm}^{-3}$ the deuteron inventory change is $d N_{i} / d t \leq 20$ torr $\cdot 1 / \mathrm{s}$ through the duration of the gas pulse, weakly falling to zero thereafter. Densities as high as $\bar{n}_{e} \simeq 1.2 \times n_{G}$, the Greenwald density limit, have been produced by gas puffing from LFS, with $d N_{i} / d t \leq 30$ torr.1/s and limited by an onset of large MHD events or a density limiting mechanism. Increasing gas injection rate and duration in fueling schemes with LFS only and a combination of LFS and HFS tend to increase the density, although the dependence is weak (Figure 3). A combination of LFS and HFS fueling with lower average rates produce higher density plasmas. The average fueling efficiency of gas injectors in NSTX is in the range $0.05-0.20$. No significant differences between LFS+HFS and LFS fueling have been found in ohmic and NBI heated L-mode discharges. The fueling efficiency does not seem to have any dependence on gas injector fueling rate. It is also independent of line density for IWL discharges, as shown in Figure 4. Diverted discharges, however, tend to achieve higher density with higher fueling efficiency. The SOL properties determines whether thermal neutrals ionize inside or outside of the LCFS thus thinner SOL in diverted discharges may result in higher penetration efficiency of the fueling particles. This subject will be further addressed when the measurements of SOL temperature, density and the deuterium ionization profile become available. Finally, we note that the fueling efficiency $\eta$ has been defined as an average quantity and the present results are valid within the 
limitatations of this definition.

NBI fueling efficiency Because of relatively low fueling rate of the NBI it is not possible to determine its fueling efficiency by global particle balance. The ionization profile of NBI is localized well within the core at $r / a \leq 0.5$, where $a$ is the minor radius. The estimated beam shine-through for NSTX plasmas is less than $10 \%$.

Impurity fueling Main impurities are boron, carbon, and oxygen. Their typical core concentrations after boronization are $0.25-0.5 \%, 1-1.5 \%$, and $0.1-0.3 \%$, respectively [3] The effective charge $Z_{\text {eff }}$ is between 1.2 and 2.5 in ohmically heated discharges and between 2 and 3.5 in NBI and HHFW heated plasmas. Impurities, therefore, contribute less than $10 \%$ to the electron density in NSTX.

\section{Comments on edge particle fluxes}

At present, NSTX utilizes conventional wall conditioning techniques for impurity and density control, including boronization and helium glow discharge cleaning [4]. The total wall inventory of a $1 \mathrm{MA} t \leq 0.5 \mathrm{~s}$ duration NSTX discharge is $\simeq 25$ torr $\cdot 1$. When the wall attains a pumping state it reduces the total inventory only by about $\leq 3$ torr.l. The development of higher performance plasmas will put emphasis on power and particle exhaust capabilities, in particular the divertor performance. NSTX divertor has an open geometry. Whereas the advantages and disadvantages of the geometry over the narrow throat divertors are debatable, it provides only two channels of particle flows: direct particle flow to the divertor plate and direct internal leakage into the main chamber. Detailed divertor characterization will commence at NSTX with commissioning of divertor probes, a bolometer array and Penning gauges. The present assessment of divertor performance is limited to impurity and ion flux estimates obtained from spectroscopic observations. Internal particle source in NSTX is dominated by neutral recycling from the wall. The recycling occurs on carbon fiber composite (CFC)-tiled surface of the center column with an area $A \leq 3.2 \mathrm{~m}^{2}$ and the divertor and passive plates with an area $A \leq 7 \mathrm{~m}^{2}$ (the actual plasma-wetted surface areas are smaller). This section describes observations and preliminary estimates of edge particle fluxes.

Neutral and ion fluxes Neutral fluxes are estimated from the pressure measurements assuming poloidal and toroidal symmetry. Ion fluxes are esti- 
mated from the measured brightness using the calculated factor of 40 ionization events per $D_{\alpha}$ photon for NSTX edge parameters $T_{e} \simeq 20-40 \mathrm{eV}$, $n_{e} \leq 5 \times 10^{12} \mathrm{~cm}^{-3}$, and the appropriate plasma surface areas. Balmer- $\alpha$ brightness is measured by two 2048-pixel filtered calibrated CCD arrays across the lower divertor and across the center stack. It is of interest to compare the magnitude of the ion and neutral fluxes at the midplane and on the divertor plates. Shown in Figure 5 are the average particle fluxes for the HFS+LFS fueled DN discharge analyzed for particle balance in Section 3. The HFS gas injection is seen at $0.08 \mathrm{~s}$ and its flux is in agreement with the neutral gas injection rate shown in Figure 2. Based on a limited database of discharges it is concluded that the ion and neutral flux at the midplane are approximately equal being on the order of $5 \times 10^{21} \mathrm{~s}^{-1}$. The divertor ion flux is $\leq 10^{23} \mathrm{~s}^{-1}$. Thus, an order of magnitude estimate indicates that the ion flux to the divertor plate greatly exceeds the radial outward ion flux in the midplane. This suggests that the radial transport near the separatrix and in the SOL is fairly low and the particle flow along the field lines to the divertor is larger than the cross-field flow. The opposite situation has been observed recently in several tokamaks and termed "main chamber recycling" [5], [6], [7]. It has been suggested that strong SOL microturbulence results in a highly non-diffusive particle transport and plasma "blob" propagation radially outward [7].

\section{Summary}

Particle balance and core fueling efficiencies of low and high field side gas fueling of L-mode ohmic and NBI heated plasmas have been compared using an analytical zero dimensional particle balance model and measured ion and neutral fluxes. Gas fueling efficiencies are in the range of $0.05-0.20$ and do not depend on discharge magnetic configuration or poloidal location of the injector. Higher densities are achieved using LFS + HFS fueling with lower average injection rates. The particle balance model indicates that the addition of HFS fueling results in a reversal of the wall loading rate. Initial particle source estimates obtained from neutral pressure and spectroscopic measurements indicate that in diverted discharges ion flux into the divertor greatly exceeds midplane ion flux from the main plasma, suggesting that SOL transport in the cross-field direction plays a minor role and the main particle flow is directed to the divertor plate. Present analysis provides the basis for detailed fluid modeling of core and edge particle flows and the analysis of particle confinement properties of L- and H-mode plasmas. 


\section{Acknowledgments}

The authors would like to thank G. Zimmer for the software development. W. Blanchard, R. Gernhardt, and P. Sichta are acknowledged for the engineering support. This research was supported by the U.S. Department of Energy under contracts No. DE-AC02-76CH03073, DE-AC05-00OR22725, and W-7405-ENG-36.

\section{References}

[1] G. Federici, C. H. Skinner, J. N. Brooks, J. P. Coad, C. Grisola, A. A. Haasz, A. Hassanein, V. Philipps, C. S. Pitcher, J. Roth, W. R. Wampler, D. G. Whyte, Nuclear Fusion 41 (12R) (2001) 1267.

[2] R. Maingi, G. L. Jackson, M. R. Wade, M. A. Mahdavi, P. K. Mioduszewski, G. Haas, M. J. Schaffer, J. T. Hogan, C. C. Klepper, Nuclear Fusion 36 (2) (1996) 245 .

[3] C. H. Skinner, H. W. Kugel, R. Maingi, W. R. Wampler, W. Blanchard, M. G. Bell, R. E. bell, D. A. Gates, S. M. Kaye, P. LaMarche, B. P. LeBlanc, J. E. Menard, D. Muller, H. K. Na, N. Nishino, F. Paoletti, S. F. paul, S. A. Sabbagh, V. A. Soukhanovskii, D. Stutman, Nuclear Fusion 42 (2002) 329.

[4] H. W. Kugel, V. A. Soukhanovskii, M. Bell, W. Blanchard, D. Gates, B. LeBlanc, R. Maingi, D. Muller, H. K. Na, S. Paul, C. H. Skinner, D. Stutman, W. R. Wampler, in: Proc. of the 15th International Conference on Plasma Surface Interactions in Controlled Fusion Devices, Gifu, Japan, May 27 - 31, 2002, 2002.

[5] M. V. Umansky, S. I. Krasheninnikov, B. LaBombard, J. L. Terry, Physics of Plasmas.

[6] B. LaBombard, M. V. Umansky, R. L. Boivin, J. A. Goetz, J. Hughes, B. Lipschultz, D. Mossessian, C. S. Pitcher, J. L. Terry, Nuclear Fusion 40 (12) (2000) 2041.

[7] A. Y. Pigarov, S. I. Krasheninnikov, T. D. Rignlien, M. J. Schaffer, W. P. West, Phys. Plasmas 9 (2002) 1287. 
Figures

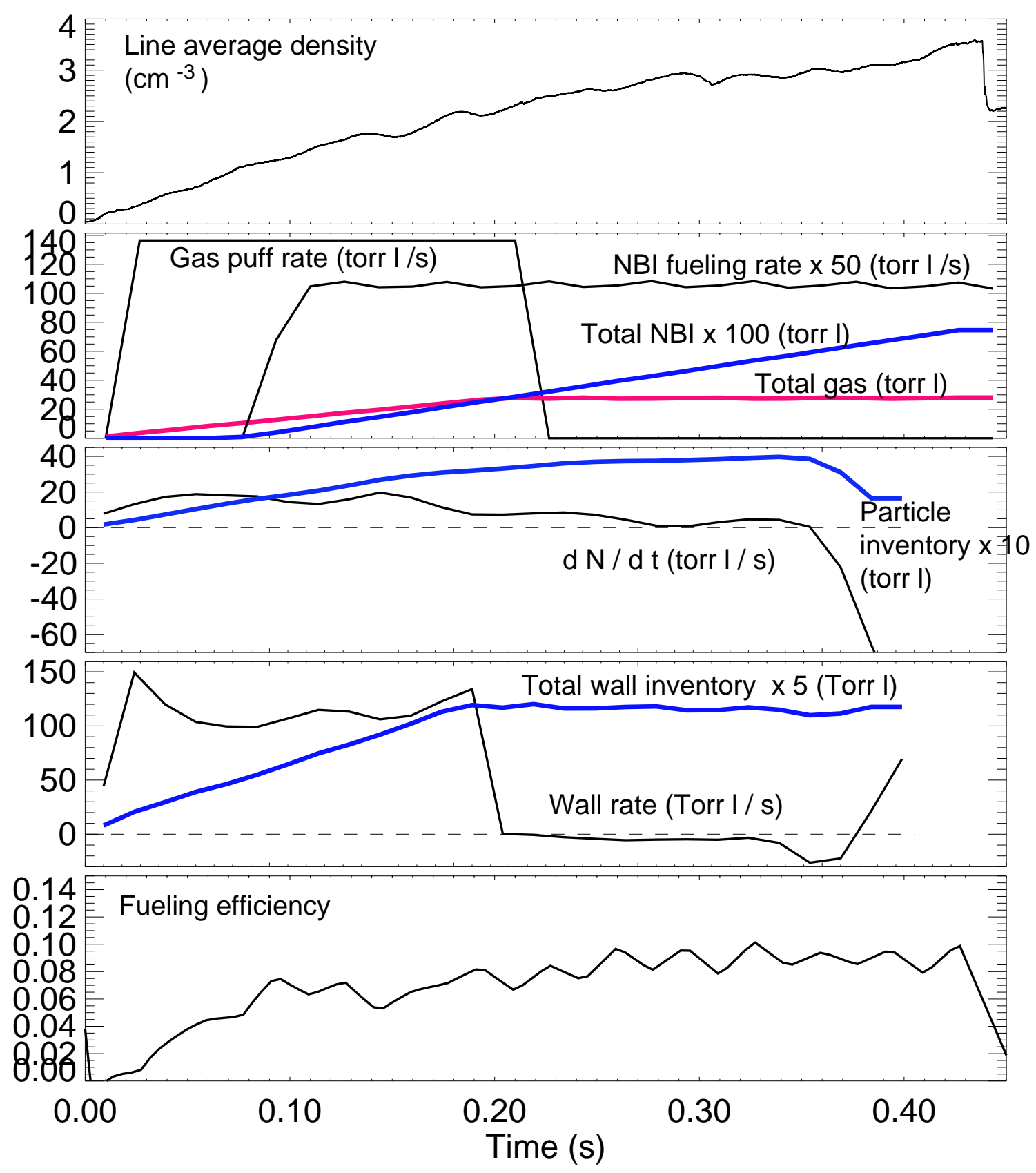

Fig. 1. Particle balance modeling of a LFS fueled discharge 


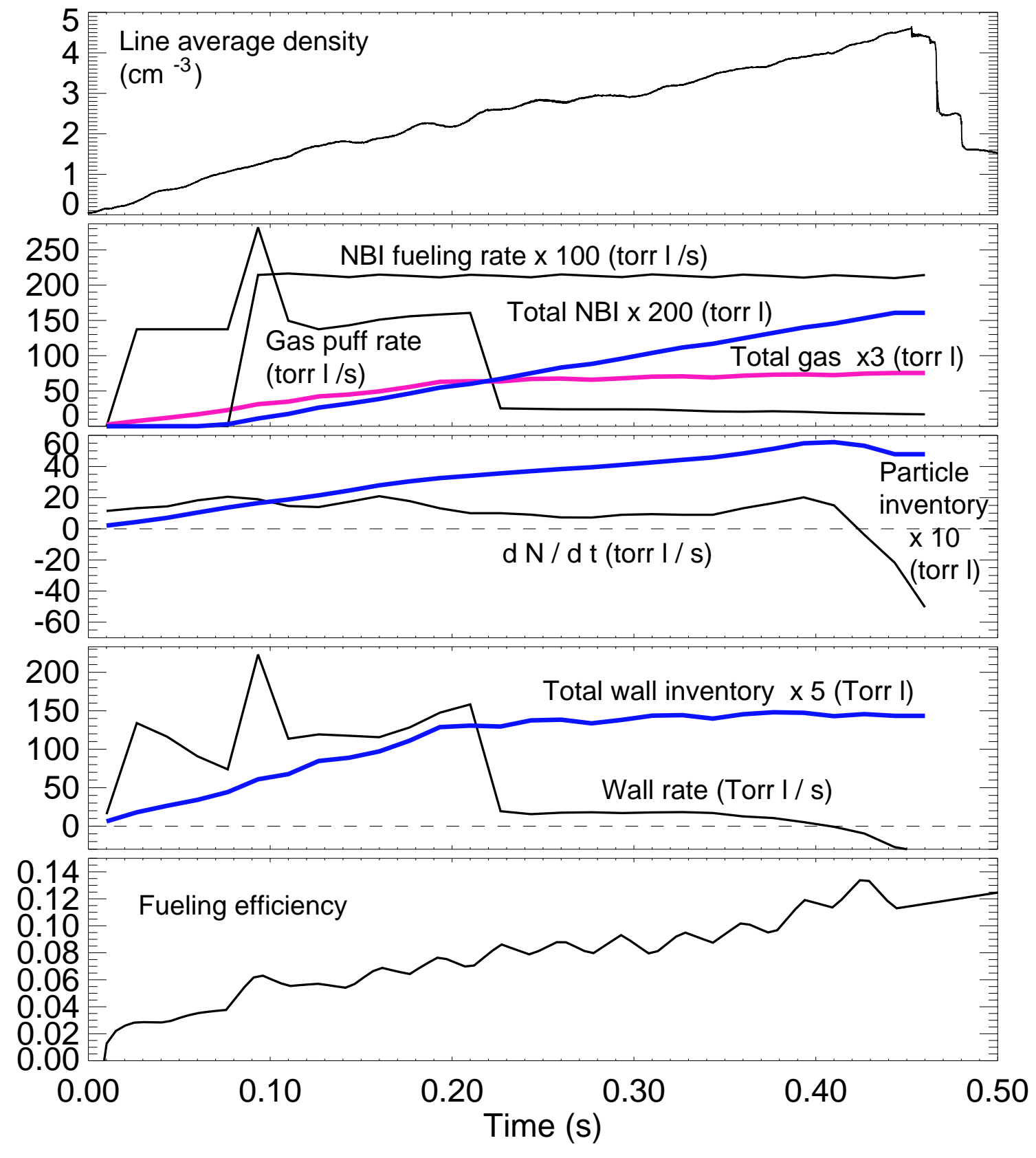

Fig. 2. Particle balance modeling of a LFS + HFS fueled discharge 


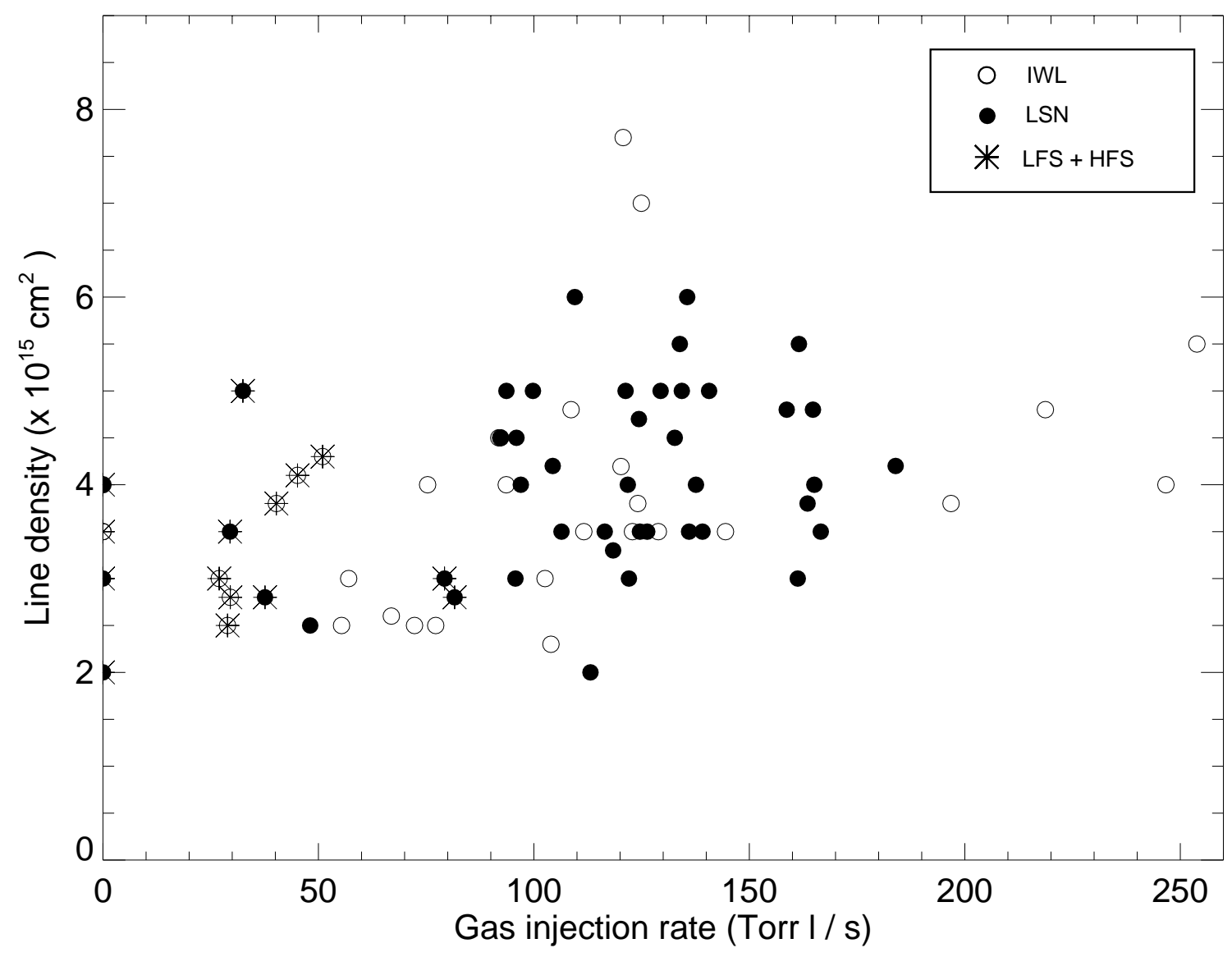

Fig. 3. Line density dependence on gas injection rate 


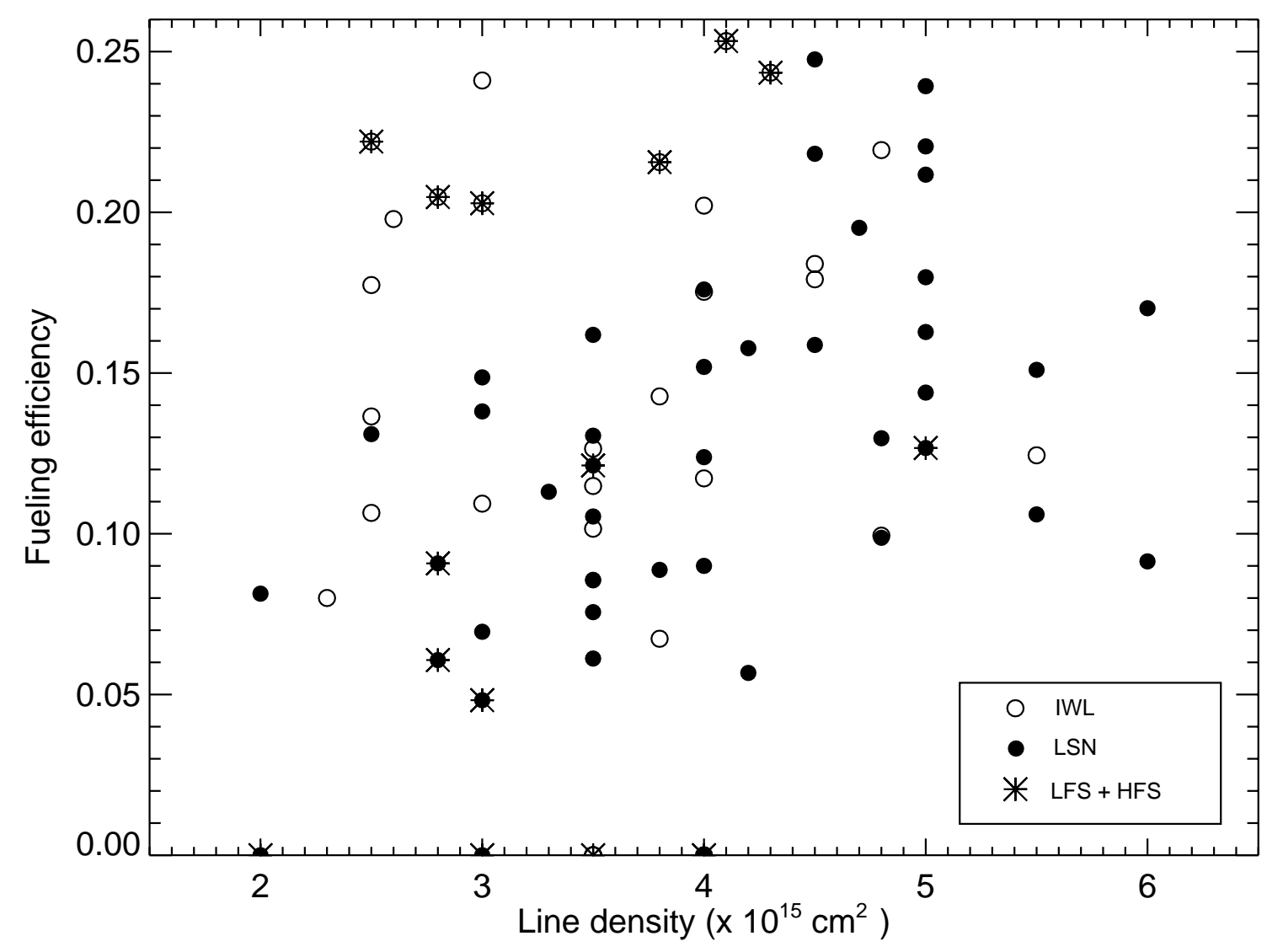

Fig. 4. Gas injection fueling efficiency dependence on line density 


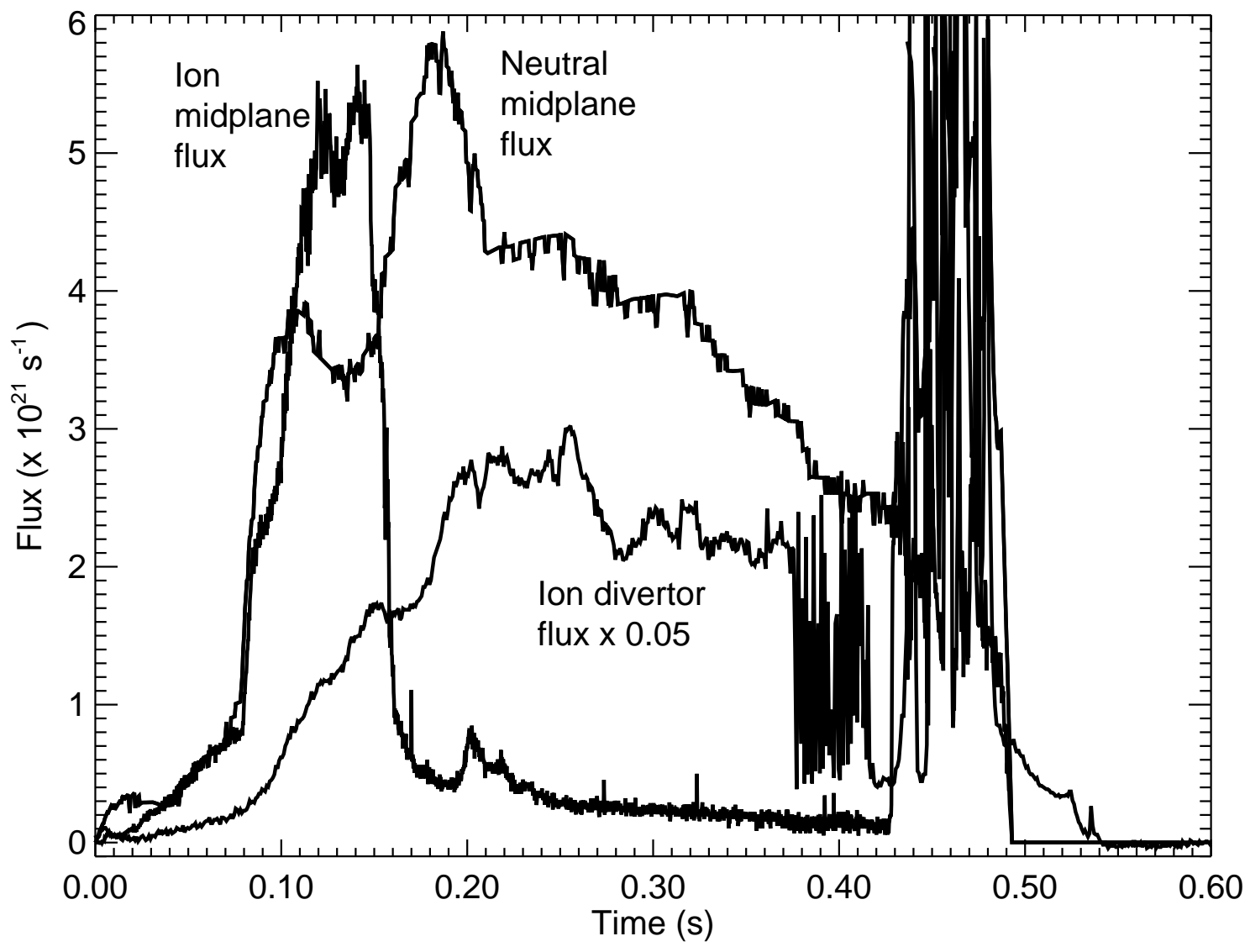

Fig. 5. Estimated ion and neutral fluxes for the discharge shown in Figure 2 


\section{External Distribution}

Plasma Research Laboratory, Australian National University, Australia

Professor I.R. J ones, Flinders University, Australia

Professor J oão Canalle, Instituto de Fisica DEQ/IF - UERJ , Brazil

Mr. Gerson O. Ludwig, Instituto Nacional de Pesquisas, Brazil

Dr. P.H. Sakanaka, Instituto Fisica, Brazil

The Librarian, Culham Laboratory, England

Library, R61, Rutherford Appleton Laboratory, England

Mrs. S.A. Hutchinson, JET Library, England

Professor M.N. Bussac, Ecole Polytechnique, France

Librarian, Max-Planck-Institut für Plasmaphysik, Germany

J olan Moldvai, Reports Library, MTA KFKI-ATKI, Hungary

Dr. P. Kaw, Institute for Plasma Research, India

Ms. P.J . Pathak, Librarian, Insitute for Plasma Research, India

Ms. Clelia De Palo, Associazione EURATOM-ENEA, I taly

Dr. G. Grosso, Instituto di Fisica del Plasma, Italy

Librarian, Naka Fusion Research Establishment, J AERI, J apan

Library, Plasma Physics Laboratory, Kyoto University, J apan

Research Information Center, National Institute for Fusion Science, J apan

Dr. O. Mitarai, Kyushu Tokai University, J apan

Library, Academia Sinica, Institute of Plasma Physics, People's Republic of China

Shih-Tung Tsai, Institute of Physics, Chinese Academy of Sciences, People's Republic of China

Dr. S. Mirnov, TRINITI, Troitsk, Russian Federation, Russia

Dr. V.S. Strelkov, Kurchatov Institute, Russian Federation, Russia

Professor Peter Lukac, Katedra Fyziky Plazmy MFF UK, Mlynska dolina F-2, Komenskeho Univerzita, SK-842 15 Bratislava, Slovakia

Dr. G.S. Lee, Korea Basic Science Institute, South Korea

Mr. Dennis Bruggink, Fusion Library, University of Wisconsin, USA

Institute for Plasma Research, University of Maryland, USA

Librarian, Fusion Energy Division, Oak Ridge National Laboratory, USA

Librarian, Institute of Fusion Studies, University of Texas, USA

Librarian, Magnetic Fusion Program, Lawrence Livermore National Laboratory, USA

Library, General Atomics, USA

Plasma Physics Group, Fusion Energy Research Program, University of California at San Diego, USA

Plasma Physics Library, Columbia University, USA

Alkesh Punjabi, Center for Fusion Research and Training, Hampton University, USA

Dr. W.M. Stacey, Fusion Research Center, Georgia Institute of Technology, USA

Dr. J ohn Willis, U.S. Department of Energy, Office of Fusion Energy Sciences, USA

Mr. Paul H. Wright, Indianapolis, Indiana, USA 
The Princeton Plasma Physics Laboratory is operated by Princeton University under contract with the U.S. Department of Energy.

\author{
Information Services \\ Princeton Plasma Physics Laboratory \\ P.O. Box 451 \\ Princeton, NJ 08543
}

Phone: 609-243-2750

Fax: 609-243-2751

e-mail: pppl_info@pppl.gov

Internet Address: http://www.pppl.gov 